[Agr. Biol. Chem., Vol. 32, No. 9, pp. 1061 1069, 1968]

\title{
Comparision of Photosensitizing Ability of Dyes in Oxidation of Histidine
}

\author{
By Toshiharu Gomyo, Yung Yang and Masao FujimakI \\ Department of Agricultural Chemistry, Fuculty of Agriculture, \\ The University of Tokyo, Tokyo \\ Received September 20, 1967
}

\begin{abstract}
Various dyes were tested in order to compare photosensitizing ability based on relative quantum yield for photosensitized oxidation of histidine. Each dye belongs to such a class as thiazine, xanthene, acridine, thiazole, phenylmethane, monoazo, azine, oxazine, porphylline and flavin. The heterocyclic structure was essential to the development of photosensitizing ability, but this ability was remarkably infuenced by introduction of substituents on aromatic rings. Fluorescence was not always accompanied with photosensitization.

Except for fluoresceine, each dye had a common feature as to $\mathrm{pH}$ dependence of photosensitized oxidation of histidine, and this reaction was dependent on electrical charge of imidazole group of histidine. Each dye also showed a common behaviour on Lineweaver-Burk's plots. Using various dyes, the photosensitized oxidation of histidine was compared with that of tryptophan, and it was found that the ratio of raction rates of both amino acids was varied with the kinds of dye. For example, the reaction rate of tryptophan was only one forth of that of histidine in the case of thionine, while in eosine no difference was shown between the reaction rate of both amino acids.
\end{abstract}

Various dyes are known to be effective in photosensitized oxidation of amino acids such as histidine, tryptophan, tyrosine, methionine and cystein. The efficiency to convert light energy into chemical reaction depends upon the chemical structure of each dye. The photo-oxidation rates of amino acids are remarkably affected by the kind of dyes, hence the relative estimation of photosensitizing ability is of much importance from the point of view that we can classify more exactly various dyes as to the photo-oxidation.

A few reports are available as to the relationship between chemical structure and the photosensitizing ability of various dyes. ${ }^{1,21}$ Results shown in these literatures, however,

1) N. Yamamoto, Virus (Osaka), 6, 522 (1956).

2) G. Oster, J.S. Bellin, R. W. Kimball and M. E. Schrader, J. Am. Chem, Soc., 81, 5095 (1959). were based not upon light intensity absorbed by the reaction system but upon dye concentration. Therefore, these don't reflect the real comparison of dyes concerning photosensitization.

Our experiments were directed towards the comparison of photosensitizing ability of various dyes and the mechanisms of photosensitizing ability of various dyes and the mechanisms of photosensitized oxidation. This was carried out by estimating the relative quantum yield using histidine as the common reactant which was as easily oxidized as tryptophan. The photosensitized oxidation reaction was followed by the manometric determination of oxygen consumption in Warburg apparatus.

\section{EXPERIMENTAL}

Illumination apparatus. Projection lamps (Kondo 
Electric Industry Co. Ltd.) were used as light sources. The power was adjusted with a voltage stabilizer from Fuji Seimitsu Denki Co. Ltd. to produce $15.1 \mathrm{~V}$ at $50 \mathrm{~W}$ where the color temperature of lamp was $3000^{\circ} \mathrm{K}$. The reaction solution was charged in a Warburg flask linked with a manometer which was set in a thermostat vessel maintained at the constant temperature of $30^{\circ} \mathrm{C}$ by circulating city water. As shown in Fig. 1, each lamp was fixed in the water of the thermostat vessel so as to illuminate the bottom of reaction flask. The mean distance between the filament of the lamp and the surface of reaction flask vibrating 120 strokes per minute was $6.0 \mathrm{~cm}$. The depth of reaction solution was adjusted to $0.5 \mathrm{~cm}$.

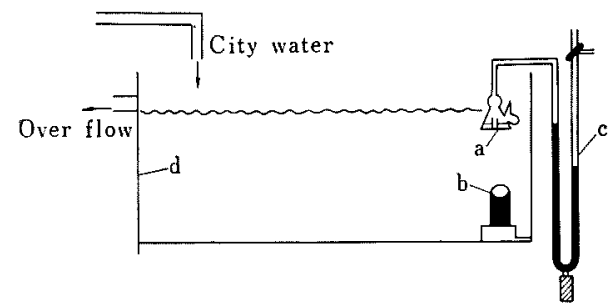

FIG. 1. Apparatus for Illumination.

The power is adjusted to produce $1.5 \mathrm{~V}$ at 50 W. Temp. $30 \pm 0.5^{\circ} \mathrm{C}$.
a: Warburg flask
b: Projection lamp
c: mano meter
d: thermostat vessel

Dyes. All dyes used were purchased from Kanto Chemical Co., Inc. These were soluble in water, which include thiazine, xanthene, acridine, thiazole, phenyl methane, monoazo, azine, oxazine, prophlline and flavin group.

Composition of reaction solution. Unless stated otherwise, the reaction mixture was prepared as follows. To $0.5 \mathrm{ml}$ of histidine hydrochloride $\left(5 \times 10^{-3} \mathrm{M}\right)$ were added $0.5 \mathrm{ml}$ of dye $\left(6 \times 10^{-3} \mathrm{M}\right)$ and $0.5 \mathrm{ml}$ of Britton-Robinson's buffer $(0.2 \mathrm{M}, \mathrm{pH} 7.0)$. The total volume was made up to $3.0 \mathrm{ml}$ with deionized water. Mixing was carried out just before illuminating operation. Reaction mixture prepared as above was poured into a main chamber of Warburg flask, and a small piece of filter paper soaked with $20 \%$ potassium hydroxide was inserted into a center cup in order to absorb carbon dioxide which was expected to evolve during illumination.

\section{RESULT}

Calculation for comparison of photosensitizing ability

Photosensitizing ability of each dye was estimated according to relative quantum yield as defined by the following expression:

$$
\Phi_{\text {rel }}=v_{0} / I_{\text {rel }} \text {. }
$$

Here, $v_{0}$ shows the initial rate of oxygen consumption $(\mu 1 / \mathrm{min})$ by reactant species, and $I_{\text {rel }}$ shows the relative number of photons absorbed by reaction system, which is ex. pressed as the following equation,

$$
I_{\mathrm{rel}}=\int_{400 \mathrm{~m} \mu}^{750 \mathrm{~m} \mu} P_{a}(\lambda) d \lambda,
$$

Where $P_{a}(\lambda)$ is the relative number of absorbed photons at the wave length of $\lambda$, and $P_{a}(\lambda)$ is obtained from the following equation.

$$
P_{a}(\lambda)_{i}=P_{i}(\lambda)(1-T) \text {, }
$$

where $P_{i}(\lambda)$ is the relative number of incident photons which was calculated from the emission spectrum of projection lamp as illustrated in Fig. 2, $T$ is transemittance which was determined using Hitachi Electro Photo Spectrometer in respect to each reaction solution. The integration for $I_{\text {rel }}$ was carried out graphically, covering all over the region of visible light from the wave length of $400 \mathrm{~m} \mu$ to that of $750 \mathrm{~m} \mu$.

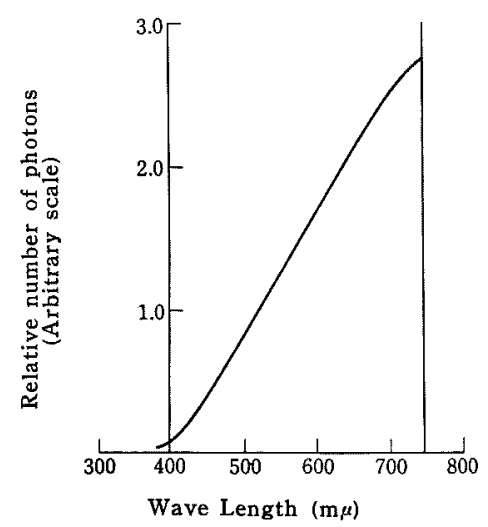

FIG. 2. Emission Spectrum of Projection Lamp Color temp. $3000^{\circ} \mathrm{K}$, lighted at $15.1 \mathrm{~V}$ and $50 \mathrm{~W}$. 
Table I. The Relation Between the Chemical Structures of Various Dayes and Their Photosensitizing Ability on Histidine

Dye and classification

Chemical structure

$\Phi_{\text {rel }}$

I. The quinonimide dyes.

1. The thiazines

Methylene blue

Thionine

Azure A

Azure B

Azure C

Toluidine blue

2. The oxazines

Nile blue

Brilliant cresyl blue

3. The azines

Neutral red

Phenosafranine<smiles>CN(C)c1ccc2nc3ccc(=[N+](C)C)cc-3sc2c1</smiles><smiles>Nc1ccc2nc3ccc(=[NH2+])cc-3sc2c1</smiles><smiles></smiles><smiles>CNc1ccc2nc3ccc(=[N+](C)C)cc-3sc2c1</smiles><smiles>C[NH+]=c1ccc2nc3ccc(N)cc3sc-2c1</smiles><smiles>Cc1cc2nc3ccc(=[N+]=[N+]=[W])cc-3sc2cc1N</smiles>

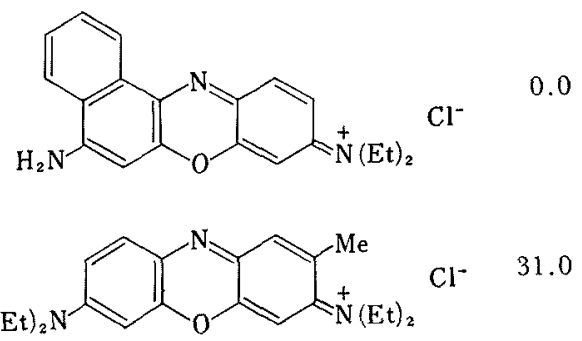<smiles>CN(C)C1=CC2=NC3=CC(=[NH2+])C([NH2+])=CC3=NC2C=C1</smiles><smiles>Nc1ccc2c(c1)nc1cc(N)ccc1[n+]2[18F]</smiles> 
II. The xantheine dyes

1. The fluorane dyes

Fluoresceine

Erythrosine

Rose bengal

Eosine $\mathrm{Y}$

2. The pyronine dyes Pyronine $\mathrm{Y}(\mathrm{G})$

Rhodamine B

III. The acridine dyes

Acridine orange

Acridine yellow

Proflavin

Acrinol<smiles>CN(C)c1ccc2cc3ccc(=[N+](C)C)cc-3[nH]c2c1</smiles><smiles></smiles>

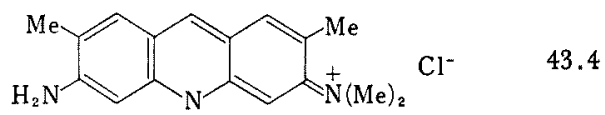<smiles></smiles>

Acriflavin<smiles>C[n+]1c2cc(N)ccc2cc2ccc(N)cc21</smiles> 
IV. The triphenyl methane dyes

Methyl violet

Light gree

Malachite green

Rosaniline

Crystal violet

V. The thiazoles

Titain yellow

Primuline yellow

VI. The mono azo dyes

Tartrazine

Methyl orange

VII. Chlorophylline

VIII. FMN
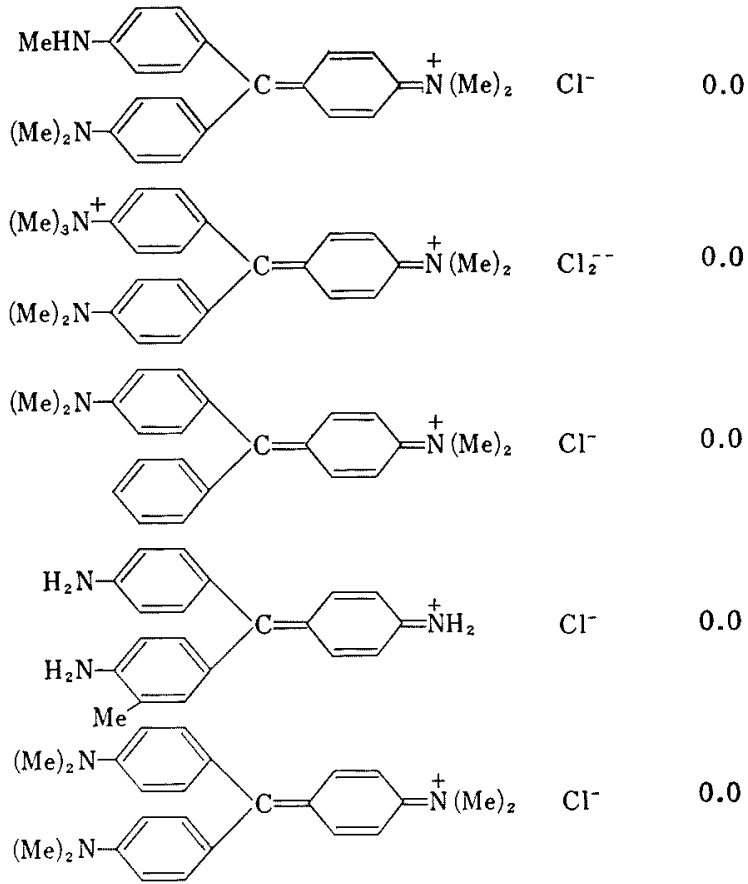

0.0

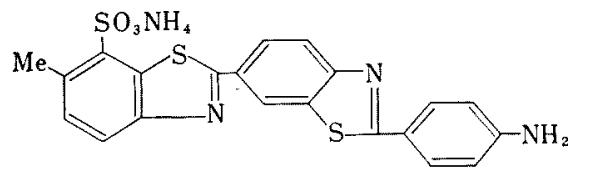<smiles>NOC(=O)c1nn(-c2ccc(S(N)(=O)=O)cc2)c(O)c1N=Nc1ccc(S(=O)(=O)O[Na])cc1</smiles><smiles>CN(C)c1ccc(N=Nc2ccc(S(=O)O[Na])cc2)cc1</smiles>

$\mathrm{CH}_{2}-\mathrm{O}-\mathrm{P}-\mathrm{OH}$

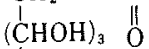
$\mathrm{CH}_{2}$<smiles>Cc1cc2nc3c(=O)[nH]c(=O)nc-3n(C)c2cc1C</smiles> 


\section{Photosensitizing ability of various Dyes}

Thirty-two dyes belonging to ten classes were tested. The vaule of photosensitizing ability of each dye was given as the ratio to that of methylene blue. Methylene blue has been used most widely as sensitizer. The results of these experiments are summarized in Table I. Many of the compounds listed are not very reactive in the usual chemical reaction. There are few common features in structure among these photosensitizers although it should be noted that most of the compounds with photosensitizing ability have heterocyclic ring structures. From this table, it can be seen that photosensitizing ability of dye is not classified, simply based on the skeleton structure. In the case of phenylmethane and monoazo groups, any substitution on the aromatic ring, however, can not result in photosensitized oxidation of histidine. These dyes have no heterocyclic ring in the structure though they are rich in $\pi$ electrons which are indispensable to put visible light energy into chemical reaction. The heterocyclic ring structure seems to be essential to photosensitizing ability. The photosensitizing ability is remarkably influenced by the substitution on aromatic rings of dye. In thiazine group, methylene blue and thionine are about two times more active than the other dyes of the same group. Substitution dependence is typically shown in xanthene group, which rises in the ability by the substitution of halogen atoms on aromatic rings and becomes powerless by that of amino groups. In this case, it may be said that electron attracting group such as halogen atoms contributes to introduction of photosensitizing ability of dyes, and to the contrary, electron group such as amino group takes off the ability of photosensitization. In acridine group, also, photosensitizing ability is altered according to the substituent group. Acriflavin is ten times more active than acridine orange although the explanation is difficult. FMN (Flavin mono nucleotide), a member of flavin group, has the greatest ability in dyes listed, and it is found to be ten times more efficient than methyleneblue, which has been taken as the stronger sensitizer than FMN and riboflavin in the photooxidation of amino acids such as histidine and tryptophan. $^{3 !}$

Fluorescence is not always essential to photosensitizing ability. For example, pyronine $Y(G)$, a member of xanthene group, has no abilty although it has strong green fluorescence. To the contrary, in the case of phenosafranine, no fluorescence can be seen though there is some ability of photosensitization. This fact suggests that photosensitizing process dose not correspond to the excited singlet state which is able to produce fluorescence.

Influences of various dyes on $\mathrm{pH}$ dependence in photosensitized oxidation

In the presence of methyleneblue, $\mathrm{pH}$

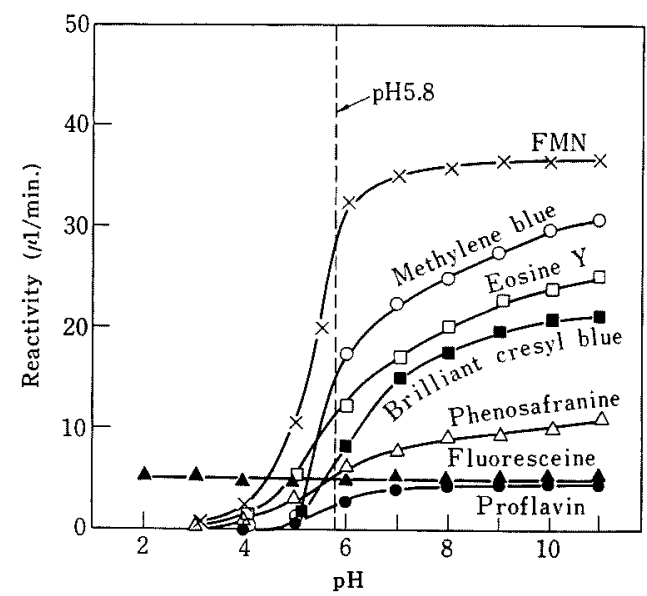

FIG. 3. Effect of $\mathrm{pH}$ on Photosensitizing Reactivity of Various Dyes.

Reaction mixtures are as follows: $0.5 \mathrm{ml}$ of $5 \times 10^{-3} \mathrm{M}$ histidine, $0.5 \mathrm{ml}$ of $6 \times 10^{-3} \mathrm{M}$ dye, 0.5 $\mathrm{ml}$ of $0.2 \mathrm{M}$ Britton and Robinson's buffer and $1.5 \mathrm{ml}$ of deimized water.

The reactivity was calculated by the estimation of initial reaction rate which was followed by oxygen consumption.

3) C. A. Ghiron and J. D. Spikes, V.S. Atomic Energy Commission Contact No. AT (11-1)-875. 
generally influences photosensitized oxidation reaction of amino acid: highly reactive in the alkaline side, low reactive in the acidic side. ${ }^{4}$ Sluyterman also showed the same tendency as mentioned above, using proflavin as sensitizer in photooxidation of histidine and tryptophan. ${ }^{51}$ As is shown in Fig. 3, the reactivity increases with the rise of $\mathrm{pH}$, and the inflection point lies about at 5.8 which is the value of $\mathrm{pk}$ of imidazole group of histidine. This figure shows that the $\mathrm{pH}$ dependence is common to every dye except fluoresceine. Therefore, it may well be said that photosensitized oxidation of histidine has a certain common mechanism which is independent of the kind of dye. The structure of dye seems not to effect the reaction scheme but to effect the reaction efficiency.

Influences of various dyes on substrate dependence in photosensitized oxidation

Figure 4 illustrates that the reciprocal of

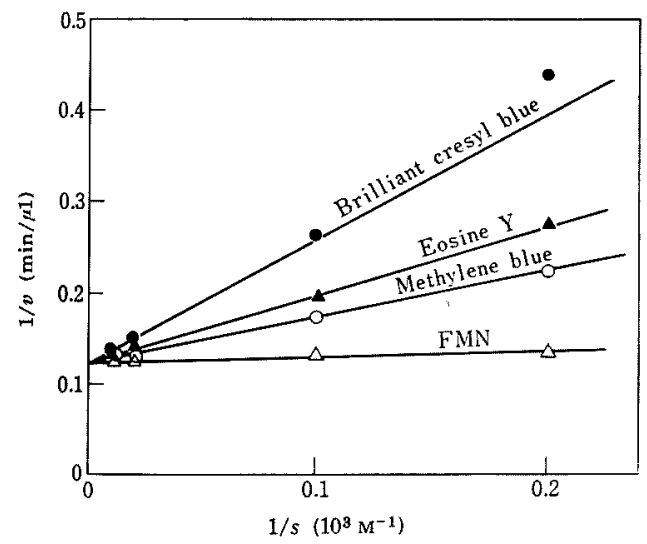

FIG. 4. Influence of Various Dyes on Substrate Concentration Dependence in Photosensitized Oxidation.

Reaction conditions are based on Experimental in this paper. The value $1 / v$ was calculated by the estimation of initial reaction rate which was followed by oxygen consumption.

4) L. Weil, T.S. Seibles and T. T. Herscovits, Arch. Biochem. Biophys., 111, 308 (1965),

5) L. A. AE. Sluyterman, Biochim. Biophys. Acta, 60, 557 (1962). the reaction rate $(1 / v)$ is linear against that of the substrate concentration $(1 / s)$. This tendency appears to be independent of the kind of dye. This implies that there are common features in reaction mechanisms among various dyes used in these experiments as well as in case of $\mathrm{pH}$ dependence. If taking Michaellis' reaction sheme into account, the slope of the line in this figure means $1 / K_{m}$, where $K_{m}$ shows the stability of active intermediate, namely Michaellis' complex, and the intersect on the axis of $1 / v$ corresponds to $1 / V_{\max }$, where $V_{\max }$ is the maximum of the reaction rate which will be attained when the concentration of the Michaellis' complex is maximal. The value of $K_{m}$ is differenent from each other according to the kind of dyes used, but $V_{\max }$ seems to be constant. Further experiment will be required to elucidate the reason why $V_{\max }$ is constant.

As will be discussed later, however, the lineality between $1 / v$ and $1 / s$ does not always involve the mechanism by Michaellis. In this figure, it should be noted only that a certain common mechanism is likely to lead the photosensitized oxidation by various dyes.

Influence of various dyes on the ratio of reaction rate between histidine and tryptophan

As is well known, tryptophan is easily oxidized by photosensitization. Tryptophan and histidine were allowed to underge photosensitized oxidation, respectively. The ratios, $v($ Try $) / v$ (His), where $v$ shows the initial reaction rate, are listed in Table II, which shows that the ratios are varied according to the kinds of dye used. In case of eosine, a powerful sensitizer, the ratio is nearly one, and this means that the selectivity of the reaction is very low. To the contrary, thionine has the much more selectivity: the reaction rate of tryptophan is only one forth of that of histidine. In addition, tryptophan is oxidized by methylene blue three times faster than by thionine although both dyes are equal as to the oxidation of histidine. This result should be remarked because it suggests that there may 
be a direct interaction between dye and amino acid in the rate regulation stage of photosensitized oxidation.

\begin{tabular}{|c|c|}
\hline \multicolumn{2}{|c|}{$\begin{array}{l}\text { TABLE II. INFLUENCES OF VARIOUS } \\
\text { THE RATIO OF REACTION RATE BET } \\
\text { HISTIDINE AND TRYPTOPHAN }\end{array}$} \\
\hline Sensitizer & $\mathrm{V}($ Try $) / \mathrm{V}($ His $)$ \\
\hline Eosine Y & 0.935 \\
\hline Brilliant cresyl blue & 0.857 \\
\hline Erythrosine & 0.847 \\
\hline Toluidine blue & 0.842 \\
\hline Methylene blue & 0.785 \\
\hline FMN & 0.782 \\
\hline Rose bengal & 0.667 \\
\hline Azure B & 0.667 \\
\hline Azure A & 0.400 \\
\hline Azure $\mathrm{C}$ & 0.440 \\
\hline Thionine & 0.250 \\
\hline
\end{tabular}

\section{DISCUSSION}

From the specific reaction velocities reported by Yamamoto, " the order of increasing effectiveness as photosensitizers against bacteriophage is as follows: $\mathrm{C}, \mathrm{C}<\mathrm{C}, \mathrm{O}<\mathrm{N}, \mathrm{N}<\mathrm{N}, \mathrm{O}$ $<\mathrm{C}, \mathrm{N}<\mathrm{N}$, $\mathrm{S}$ in meso atoms of anthracence-likecompounds. This, however, doesn't agree with our result as is shown in Table I., although it should be noted that there may be some difference between histidine and nucleic acid. This difference probably comes partly from the method how to estimate photosensitizing ability. The order above mentioned represents that of increasing absorption coefficient of dye, but does not mean the degree of the net ability of photosensitizer, because the real light intensity absorbed by reaction system is not taken into consideration. It is reasonable to say that substituents on aromatic nucleae have more power over the photosensitizing ability than skeleton structures. Recent works by several investigators ${ }^{6,7)}$ have

6) N. K. Bridge and G. Porter, Proc. Roy. Soc., 244, 276, (1958).

7) C. G. Hatehard and C. A. Parker, Trans. Farad. Soc., 57, 1093 (1961). come to the conclusion that photosensitizes plays part in oxidation through its triplet statt which follows excited singlet state. There. fore, chemical energy useful for photosen sitization has its origin not in excited singlet state which is able to emit fluorescence energy, but in triplet state, namely source of phosphorescence. It is not much significant whether the dye is fluorescent or not in order to classify dyes on the base of photosensitizing ability.

The mechanism leading the photosensitized oxidation of histidine and trytophan appears to be different from that proposed by Kopecky ${ }^{\text {RI }}$ who studied the oxidation of oleffin using several dyes. His mechanism proposed is as follows.

$$
\begin{aligned}
& \text { Dye } \stackrel{{ }^{k \nu}}{\longrightarrow} \text { Dye }^{*}(\text { singlet }) \\
& \text { Dye } \left.^{*} \longrightarrow \text { Dye }^{* *} \text { (triplet }\right) \\
& \text { Dye }^{* *}+\mathrm{O}_{2} \longrightarrow \text { Dye }+\mathrm{O}_{2}{ }^{*} \\
& \mathrm{O}_{2}{ }^{*}+\text { substrate } \longrightarrow \text { oxidation product }
\end{aligned}
$$

The reason for this scheme is based on the fact that the ratio of reaction rate of two kinds of oleffin compounds used as substrate is constant in case of various dyes. In this scheme, the direct interaction between dye and substrate plays no part in photosensitized oxidation. From this fact, it may as well be concluded that Kopecky's reaction mechanism can not elucidate our data on the photosensitized oxidation of histidine and tryptophan. Although further investigation is required, it is indicated that there may be some active intermediate which is produced from the formation of dye-substrate complex in case of photosensitized oxidation of amino acids such as histidine and tryptophan. This assumption fits the linearity of Lineweaver-Burk's plot (Fig. 4). For all that, it should be remarked that the competitive reaction generally holds the linear relatioship between $1 / v$ and $1 / s$ without any assumption of active complex like

8) K. R. Kopecky and H. J. Reich, Can. J. Chem., 43, 2265 (1965). 
that of Michaellis. ${ }^{21}$

From Fig. 3, it is apparent that there is a close relationship between photosusceptible site of histidin and imidazole-ring which corresponds to indole group of tryptophan. The dissociation equilibrium of imidazole group is indicated as follows. Below $\mathrm{pH} 5.8$, the cationic form is predominant and the photosensitizing reactivity falls to be nearly negligible. This fact supports the speculation proposed by Sluyterman who argued that photosensitized oxidation was an electrophilic reaction. Here it should be noted that the molecular form of dye varies with $\mathrm{pH}$, because each dye has some dissociable groups, basic or acidic, which result in water soluble property of dyes. From these facts, the $\mathrm{pH}$ dependence of dyes appear to play less part in photosensitezed oxidation than that of imidazole ring. A strange tendency can be seen in case of fluoresceine where no relationship exists between $\mathrm{pH}$ and photosensitizing reactivity. This is still under investigation.

Acknowledgements. The authors wish to express their appreciation to Prof. Y. Sakurai, Nihon Women's University for his helpful suggestion. They are also grateful to $\mathrm{Mr}$. T. Mishima for taking the emission spectrum of projection lamp. 